Asian Pacific Journal of Tropical Medicine

doi: $10.4103 / 1995-7645.318304$

Impact Factor: 1.94

\title{
Ivermectin as an adjunct treatment for hospitalized adult COVID-19 patients: A randomized multi-center clinical trial
}

Morteza Shakhsi Niaee ${ }^{1}$, Peyman Namdar ${ }^{2}$, Abbas Allami ${ }^{3}$, Leila Zolghadr ${ }^{4}$, Amir Javadi ${ }^{5}$, Amin Karampour ${ }^{3}$, Mehran Varnaseri ${ }^{6}$, Behzad Bijani ${ }^{7}$, Fatemeh Cheraghi ${ }^{1}$, Yazdan Naderi ${ }^{8}$, Fatemeh Amini ${ }^{9}$, Masoumeh Karamyan ${ }^{6}$, Mohammad Jafar YadYad ${ }^{6}$, Ramin Jamshidian ${ }^{6}$, Nematollah Gheibi ${ }^{8 凶}$

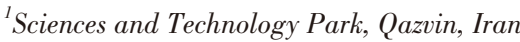

${ }^{2}$ Department of Surgery, Qazvin University of Medical Sciences, Qazvin, Iran

${ }^{3}$ Department of Infectious Diseases, Clinical Research Development Unit, BouAliSina Hospital, Qazvin University of Medical Sciences, Qazvin, Iran

${ }^{4}$ Department of Chemistry, Imam Khomeini International University Qazvin, Iran

${ }^{5}$ Department of Social Sciences School of Medicine, Qazvin University of Medical Sciences, Qazvin, Iran

${ }^{6}$ Infectious and Tropical Diseases Research Center, Ahvaz Jundishapur University of Medical Sciences, Ahvaz, Iran

${ }^{7}$ Department of Infectious Diseases, Qazvin University of Medical Sciences, Qazvin, Iran

${ }^{8}$ Cellular and Molecular Research Center, Research Institute for Prevention of Non-Communicable Diseases, Qazvin University of Medical Sciences, Qazvin, Iran

${ }^{9}$ Department of Persian Medicine, School of Medicine, Shiraz University of Medical Sciences, Shiraz, Iran

\section{ABSTRA C T}

Objective: To evaluate different doses of ivermectin in adult patients with mild COVID-19 and to evaluate the effect of ivermectin on mortality and clinical consequences.

Methods: A randomized, double-blind, placebo-controlled, multicenter clinical trial was performed at five hospitals. A total of 180 mild hospitalized patients with COVID-19 confirmed by PCR or chest image tests were enrolled and allocated to six arms including hydroxychloroquine $200 \mathrm{mg}$ twice per day, placebo plus hydroxychloroquine $200 \mathrm{mg}$ twice per day, single dose ivermectin $(200 \mu \mathrm{g} / \mathrm{kg})$, three low interval doses of ivermectin (200, 200, $200 \mu \mathrm{g} / \mathrm{kg})$, single dose ivermectin $(400 \mu \mathrm{g} / \mathrm{kg})$, and three high interval doses of ivermectin $(400,200,200 \mu \mathrm{g} / \mathrm{kg})$. The primary endpoint of this trial was all-cause of mortality or clinical recovery. The radiographic findings, hospitalization and low $\mathrm{O}_{2}$ saturation duration, and hematological variables of blood samples were analyzed.

Results: A total of $16.7 \%$ (5/30) and $20.0 \%$ (6/30) patients died in arms treated with hydroxychloroquine $200 \mathrm{mg}$ twice per day and placebo plus hydroxychloroquine $200 \mathrm{mg}$ twice per day, respectively, and a reduction in mortality rate in patients receiving ivermectin treatment to $0 \%, 10 \%, 0 \%$ and $3.3 \%$ for arms 1-4 were observed. Risk of mortality was also decreased about $15 \%$ in the ivermectin treated arms.

Conclusions: Ivermectin as an adjunct reduces the rate of mortality, time of low $\mathrm{O}_{2}$ saturation, and duration of hospitalization in adult COVID-19 patients. The improvement of other clinical parameters shows that ivermectin, with a wide margin of safety, had a high therapeutic effect on COVID-19.

KEYWORDS: SARS-COV-2; Ivermectin; Randomized controlled trial; Dose-respond relationship

\section{Introduction}

The COVID-19 disease has become a pandemic after the WHO declaration in March 2020. This disease has created a difficult condition around the world, and hence there is an important and urgent need to find proper treatments for an effective cure, decrease the virus carriage duration, and thus limit its transmission in society[1-3]. So far, different drugs such as hydroxychloroquine, azithromycin, remdesivir, oseltamivir, lopinavir, and ritonavir have been used against COVID-19[4-10]. However, among the candidate treatments, only remdesivir have been tested in large

To whom correspondence may be addressed. E-mail: gheibi_n@yahoo.com, ngheibi@qums.ac.ir

This is an open access journal, and articles are distributed under the terms of the Creative Commons Attribution-Non Commercial-ShareAlike 4.0 License, which allows others to remix, tweak, and build upon the work non-commercially, as long as appropriate credit is given and the new creations are licensed under the identical terms.

For reprints contact: reprints@medknow.com

(C2021 Asian Pacific Journal of Tropical Medicine Produced by Wolters KluwerMedknow. All rights reserved.

How to cite this article: Shakhsi Niaee M, Namdar P, Allami A, Zolghadr L, Javadi A, Karampour A, et al. Ivermectin as an adjunct treatment for hospitalized adult COVID19 patients: A randomized multi-center clinical trial. Asian Pac J Trop Med 2021; 14(6): 266-273.

Article history: Received 12 December $2020 \quad$ Revision 31 May 2021 Accepted 4 June 2021
Revision 31 May 2021
Available online 25 June 2021 